\title{
Laboratory Sample Manual
}

National Cancer Institute

\section{Source}

National Cancer Institute. Laboratory Sample Manual. NCI Thesaurus. Code C115541.

Documentation describing work processes and procedures for the collection, handling, and shipping of a sample. 